\title{
International Health Professional Migration and Brain Waste: A Situation of Double-Jeopardy
}

\author{
Nazmul Alam1 ${ }^{*}$, Lisa A. Merry², Mohammad Mainul Islam²,3, Claudia Z. Cortijo ${ }^{4}$ \\ ${ }^{1}$ Research Centre of the University of Montreal Hospital (CR-CHUM), Quebec, Canada \\ ${ }^{2}$ Ingram School of Nursing, McGill University, Montreal, Quebec, Canada \\ ${ }^{3}$ Department of Population Sciences, University of Dhaka, Dhaka, Bangladesh \\ ${ }^{4}$ Department of Geography, McGill University, Montreal, QC, Canada \\ Email: ${ }^{\text {nazmul.alam@umontreal.ca }}$
}

Received 24 February 2015; accepted 16 March 2015; published 20 March 2015

Copyright (C 2015 by authors and Scientific Research Publishing Inc.

This work is licensed under the Creative Commons Attribution International License (CC BY). http://creativecommons.org/licenses/by/4.0/

(c) (i) Open Access

\begin{abstract}
The migration of health professionals from low- and middle-income to high-income countries has received much attention amongst the global health community as an important factor influencing health care systems. There is however, much less dialogue about internationally trained health professionals who are not able to practice their professions in their countries of destination, a phenomenon labelled as "brain waste". It has been shown that the integration of internationally trained health professionals in their country of destination is hindered due to inadequate language skills, a lack of local work experience, cultural incompetency, and barriers to the recognition of credentials from foreign academics and professionals. To maximize gains from migration of health professionals and to minimize the negative impacts, we need policies with proper guidelines for practical strategies to better integrate health professional immigrants into the workforce of destination countries. These policies and action plans should also foster healthcare system capacity building and appropriate compensation in low- and middle-income countries
\end{abstract}

\section{Keywords}

Health Professional, Migration, Brain Waste

${ }^{*}$ Corresponding author.

How to cite this paper: Alam, N., Merry, L.A., Islam, M.M. and Cortijo, C.Z. (2015) International Health Professional Migration and Brain Waste: A Situation of Double-Jeopardy. Open Journal of Preventive Medicine, 5, 128-131.

http://dx.doi.org/10.4236/ojpm.2015.53015 


\section{Introduction}

Health professionals, particularly those from low- and middle-income countries (LMICs), have historically been targeted for immigration by many high income countries. Nurses, doctors and biomedical researchers constitute the majority of health professional migration worldwide. According to a World Health Organisation (WHO) report, Australia, Canada, United Kingdom and United-States together account for $72 \%$ of foreign-born nurses and $69 \%$ of foreign-born doctors [1]. There are plenty of reports that highlight the extent, magnitude, and consequences of health professional migration from LMICs to high-income countries. However, less focus has been given to the numerous accounts of internationally trained health professionals who are not able to practice their professions in their countries of destination, a phenomenon labelled as "brain waste". We argue that the repercussions of "brain waste" cause a situation of double-jeopardy that needs further attention among global health advocates. On one side, it leads to greater difficulty for these individuals and their families to succeed and to contribute to their destination countries. On the other side, it has a negative impact on healthcare systems in the countries of origin.

In their 2012 report, Kasper and Bajunirwe concluded that in half of the countries in sub-Saharan Africa, more than $30 \%$ of the physicians trained locally are "lost" as a consequence of migration. Zimbabwe, for example lost 1200 physicians that were trained between 1990 and 2001 due to international migration, leaving only 360 in the country as of 2006 [2]. Similarly, a very large portion of health care providers trained in smaller and poorer countries in the Caribbean and Central America have migrated to the United States. South-East Asia is another region that has been gravely affected by similar circumstances [3]. The Philippines face a massive shortage of nurses, and the country now promotes and has even institutionalized the export of health professionals, creating an even direr situation [4]. Despite the active recruitment of these professionals however, a significant proportion fail to integrate into their own professions and fields once they arrive in the new country. This short communication aims to generate further attention of the stakeholders for better polices and pragmatic action plans to better handle the situation of international health professional migration and brain waste.

\section{Causes and Consequences of Health Professional's Migration}

The most critical consequence of the outbound migration of skilled health professionals is the impact that it has on the availability and quality of health services, especially in the public sector and rural communities in LMICs. The World Health Organization (WHO) has estimated a shortage of 4.3 million health care providers globally, with the poorest countries being most severely affected [5]. The WHO identified 57 countries that fail to meet the minimum requirements of 23 doctors/10,000 population. Out of these 57 countries, 36 were in Africa [6]. LMICs are therefore unable to achieve health targets through the delivery of core public health services, including those related to maternal and child health, immunizations, HIV/AIDS, tuberculosis. This causes major disruptions in their biomedical research infrastructures [2]. Most striking is the fact that $65 \%$ of the available health care providers in the world are in North American and European countries, yet they only bear $20 \%$ of the global disease burden. African countries, on the other hand, have only 3\% of the global health workforce yet bear $24 \%$ of the global disease burden [5].

There are various reasons why health professionals decide to migrate to high-income countries. These are mostly explained by "push" and "pull" factors [7] [8]. The "pull" factors include the prospect of better and more comfortable living and working conditions, higher wages and better education for their children. Conversely, poor wages, economic instability, health risks and social safety concerns are the factors that "push" health care personnel to leave their countries. Whatever the reasons for migration may be, the brain waste of internationally trained health professionals is an undesirable consequence of migration policies adopted by developed countries, and is one which warrants greater attention from global health communities.

\section{Perspective of Canada}

Canada is one of the many high-income countries known to pursue and rely on immigrant health professionals to fill demands in its healthcare system. Canadian immigration policy uses a point system that prioritizes younger, highly-skilled, educated, and English or French speaking immigrants that are considered to be able to contribute to the economic growth of the country. An alarming proportion of doctors and nurses that are selected for immigration, however, are not successful in obtaining employment in their professions. This is the case despite de- 
plorable waiting lists to receive healthcare/specialist services and the numerous nursing positions that need to be filled. As 15.3\% of Canadians reported being without a family physician in 2011, this should be a core discussion point for mitigation of such a crucial unmet healthcare need in Canada [9]. Instead, these health professionals are unemployed or underemployed, working low-skill jobs such as nurse auxiliaries/patient-assistants, taxi drivers, pizza deliverers or so called "survival jobs" or "odd jobs” [10]. A magazine article titled "Taxi Driver Syndrome”. reported that the problem of brain waste costs Canada as totaling \$3 billion a year [11].

It has been shown that the integration of internationally trained health professionals in their country of destination is hindered due to inadequate language skills, a lack of local work experience and cultural incompetency. Barriers to the recognition of foreign academic and professional credentials are also considered as key impediments to the integration of health professionals in their destination countries. The result is increased frustration and stress for these individuals and their families, and an overall poor quality of life. Respective countries are more or less aware of this issue and thus updating strategies to minimise the effect of such an important capital loss in already jeopardised global supply of health professional. For example, federal government in Canada invested \$50 million in 2009 to improve foreign qualification recognition program for efficient integration but we need strong follow up mechanism to monitor impact of such initiatives [12].

\section{Conclusions and Recommendations}

To maximize gains from migration and to minimize the negative impacts, we need policies that not only support the better integration of health professional immigrants into the workforces of destination countries, but those which also foster healthcare system capacity building in LMICs. For better integration, efficient bridging programs need to be created which focus on language training, address financial difficulties through loan programs, make information available at various levels, and provide skills for gaining cultural competence [13]. The code of practice that the WHO has developed in 2010 on the international recruitment of health professionals should be used as a guide for action to strengthen the health workforce and health systems [14]. The 67th World Health Assembly adopted the Recife political declaration. It also mandates the WHO to develop a global strategy on human resources for health in order to position the health workforce centrally in the post-2015 health development agenda [15]. Implementation of effective programs and policies in the destination countries would best be achieved through dialogue with stakeholders, strong commitment of policy makers and guidance from the respective international organizations including the International Organization of Migrants, the International Labour Organization and the World Health Organization to maximize gains from migration of health professionals and to minimize the negative impacts on involved parties.

\section{Acknowledgements}

This work is supported by the Global Health Capacity Strengthening Program (GHR-CAPS), a project funded by the Canadian Institutes of Health Research and the Quebec Population Health Research Network.

\section{Conflict of Interest Statement}

The authors declare that they have no competing interests.

\section{References}

[1] World Health Organization (2013) The Health Workforce: Advances in Responding to Shortages and Migration, and in Preparing for Emerging Needs. Report by the Secretariat to the World Health Assembly.

[2] Taylor, A.L., Hwenda, L., Larsen, B.I. and Daulaire, N. (2011) Stemming the Brain Drain-A WHO Global Code of Practice on International Recruitment of Health Personnel. The New England Journal of Medicine, 365, $2348-2351$. http://dx.doi.org/10.1056/NEJMp1108658

[3] Kanchanachitra, C., Lindelow, M., Johnston, T., Hanvoravongchai, P., Lorenzo, F.M., et al. (2011) Human Resources for Health in Southeast Asia: Shortages, Distributional Challenges, and International Trade in Health Services. Lancet, 377, 769-781. http://dx.doi.org/10.1016/S0140-6736(10)62035-1

[4] Lorenzo, F.M., Galvez-Tan, J., Icamina, K. and Javier, L. (2007) Nurse Migration from a Source Country Perspective: Philippine Country Case Study. Health Services Research, 42, 1406-1418.

http://dx.doi.org/10.1111/j.1475-6773.2007.00716.x 
[5] Organization, W.H. (2010) Migration of Health Workers. World Health Organization, Geneva.

[6] Kasper, J. and Bajunirwe, F. (2012) Brain Drain in Sub-Saharan Africa: Contributing Factors, Potential Remedies and the Role of Academic Medical Centres. Archives of Disease in Childhood, 97, 973-979. http://dx.doi.org/10.1136/archdischild-2012-301900

[7] Poppe, A., Jirovsky, E., Blacklock, C., Laxmikanth, P., Moosa, S., et al. (2014) Why Sub-Saharan African Health Workers Migrate to European Countries That Do Not Actively Recruit: A Qualitative Study Post-Migration. Glob Health Action, 7, 24071.

[8] Aiken, L.H., Buchan, J., Sochalski, J., Nichols, B. and Powell, M. (2004) Trends in International Nurse Migration. Health Affairs (Millwood), 23, 69-77. http://dx.doi.org/10.1377/hlthaff.23.3.69

[9] Islam, N. (2014) The Dilemma of Physician Shortage and International Recruitment in Canada. International Journal of Health Policy and Management, 3, 29-32. http://dx.doi.org/10.15171/ijhpm.2014.53

[10] Bourgeault, I.L., Neiterman, E. and Lebrun, J. (2011) Midwives on the Move: Comparing the Requirements for Practice and Integration Contexts for Internationally Educated Midwives in Canada with the U.S., U.K. and Australia. Midwifery, 27, 368-375. http://dx.doi.org/10.1016/j.midw.2011.03.010

[11] Reitz, J.G. (2011) Taxi Driver Syndrome: Behind-the-Scenes Immigration Changes Are Creating New Problems on Top of Old Ones.

[12] Immigrant, C. (2014) Top Health Care Careers in Demand.

[13] Bourgeault, I.L., Neiterman, E., LeBrun, J., Viers, K. and Winkup, J. (2011) BRAIN GAIN, DRAIN \& WASTE: The Experiences of Internationally Educated Health Professionals in Canada. University of Ottawa, Ottawa.

[14] World Health Organization (2010) WHO Global Code of Practice on the International Recruitment of Health Personnel. Geneva.

[15] Global Health Workforce Alliance (2014) News Release 2014. 